Research Article

\title{
Application of Distributed Optical Fiber Technology for Coal Bump Prevention
}

\author{
Han Liang $\left(\mathbb{D}\right.$, Jun Han $\mathbb{D}^{\mathbb{D}}$, and Zuoqing Bi \\ College of Mining Engineering, Liaoning Technical University, Fuxin 123000, China \\ Correspondence should be addressed to Han Liang; 18641822228@163.com
}

Received 3 June 2021; Accepted 3 July 2021; Published 9 July 2021

Academic Editor: Chun Zhu

Copyright ( 92021 Han Liang et al. This is an open access article distributed under the Creative Commons Attribution License, which permits unrestricted use, distribution, and reproduction in any medium, provided the original work is properly cited.

The 8939 working face in Xinzhouyao coal mine is a high coal bump proneness panel. For coal bump prevention, rib holes are drilled for pressure relief purpose. The deformational behaviour of the pressure relief borehole is studied using distributed optical fiber sensing technology. The strain of the surrounding coal and the pressure relief range were measured from $0 \mathrm{hrs}$ to $402 \mathrm{hrs}$ after hole drilling. Based on the analysis of pressure relief procedure, combining with borehole observation, the crack development, limited equilibrium, collapse, and compaction stages of the borehole were estimated as $0 \sim 72 \mathrm{~h}, 72 \sim 190 \mathrm{~h}, 190 \sim 402 \mathrm{~h}$, and greater than $402 \mathrm{~h}$, respectively. Consequently, the hole drilling is modified to $110 \mathrm{~m}$ ahead of the working face to achieve better pressure relief effect. Microseismic monitoring shows that, after hole drilling optimisation, the high-energy microseismic events and average energy of microseismic events are reduced significantly.

\section{Introduction}

Along with increasing mining depth, geodynamic disasters, such as coal bump and coal and gas outburst, become one major issue that threaten mining safety and economy for underground coal mining industry [1-4]. Among them, coal bump occurred at 132 underground coal mines in China. This geodynamic disaster is closely relative to high ground stress and stress concentration around the coal pillar in the case of mulitseam mining [5-7].

Dynamic disasters are induced by stress change, including abutment pressure, circular loading, and unloading, which are closely related to the stability of surrounding rock [8-11]. For dynamic disaster prevention, pressure relief measures are often employed, which mainly include borehole drilling, injection, coal seam blasting, roof blasting, and floor blasting [12-16]. Among them, borehole drilling is an easy, quick manner that does not affect mining operation. It releases rib coal stress directly that prevents coal bumps effectively.

In literature, the effect of pressure relief induced by the drilling hole was studied using analytical, numerical, or electromagnetic radiation methods [17-26]. It was found that stress was concentrated on the hole perimeter after the hole was drilled; coal mass around the borehole formed crushing area, plastic deformation area, and elastic deformation area. As a result, the potential energy within the coal seam was released and the possibility of coal bump was reduced [17]. However, there is lack of accurate measurement technology to monitoring the deformation procedure of surrounding coal quantitively.

Several new sensing technologies have been developed to monitoring the stress changes in underground coal mining [27-31]. Distributed optical fiber sensing is one of them based on spontaneous Brillouin scattering principle. It is now being used in geotechnical engineering such as overburden subsidence measurement in coal mining industry [32-34]. In this study, BOTDR distributed optical fiber sensing technology is being used to monitoring the effect of pressure relief of drilling hole. Along the tailgate of one working face with high coal bump proneness, optical fiber was installed into the coal mass of the tailgate rib. Holes for pressure releasing were drilled beneath the optical fiber. Regular measurement of the deformation of surrounding coal was undertaken, combining with observation of the crushing procedure of the drilling holes. This study investigates borehole deformation and also technical aspects of application of distributed optical fiber sensing technology in coal bump prevention. 


\section{BOTDR Measurement Principle}

BOTDR can measure the temperature or strain distribution along the entire fiber by sensing the frequency drift of back Brillouin scattered light. When the axial strain or peripheral temperature of the fiber changes, the frequency of the Brillouin scattered light along the fiber drifts linearly. As the temperature change in coal mine is negligible, the relationship can be expressed as $[35,36]$

$$
v_{B}(\varepsilon)=v_{B}(0)+\frac{\mathrm{d} v_{B}(\varepsilon)}{\mathrm{d} \varepsilon} \times \varepsilon,
$$

where $\varepsilon$-strain; $v_{B}(\varepsilon)$-frequency of Brillouin light while strain is $\varepsilon$; $v_{B}(0)$-initial Brillouin scattered light; $\left(\mathrm{d} v_{B}(\varepsilon) / \mathrm{d} \varepsilon\right)$-ratio.

BOTDR sensor fiber is waterproof, moisture resistance, antielectromagnetic interruption, corrosion resistance, and flexible. After implanting a single-mode fiber into the coal mass, its deformation can be measured along the fiber through a demodulator. The measurement is accurate, real time, and continuous.

The ground stress of the coal mass is redistributed after a hole is drilled [37]. Finally, the borehole is filled with crushed coal; and crushing zone, plastic zone, elastic zone are formed from inside to outside of the borehole, as shown in Figure 1.

In the field, the optical fiber was installed above the pressure relief borehole. The fiber is glued with the surrounding coal so that the deformational behaviour of the coal mass can be calculated using axial strain data of the fiber. From the Brillouin light measurement principle, a positive value of the fiber strain is in the state of tension and a negative strain indicates compression of the fiber. According to the fixed beam theory [38, 39], the middle section of the sensing fiber is in tensile state, and the bending moment in this section is positive; at the two ends of the fiber, the bending moment is negative. Therefore, the point of zero bending moment along the sensor fiber indicates the boundary of the pressure relieving area of the borehole. According to the geometry illustrated by Figure 1, the effective pressure relief range can be calculated using

$$
R=\sqrt{h^{2}+\left(\frac{L}{2}\right)^{2}}
$$

where $L$ is the length strain $>0 ; R$ is the relief radius; $h$ is the distance between pressure relief borehole center and sensing optical cable.

\section{Field Testing}

3.1. Field Conditions. Xinzhouyao coal mine is located in the Datong coalfield. The eastern part of the Datong coalfield is adjacent to Kouquan Fault, whose tectonic movement accumulates potential energy that induces coal bump in the mining procedure. Coal bumps occurred in coal mines around Kouquan fault such as Meiyukou, Yizhou, and Tongjialiang coal mines.

The 8939 working face is in west $2^{\text {nd }}$ mining district mainly mining $11 \#$ coal seam. Its western side is 8937

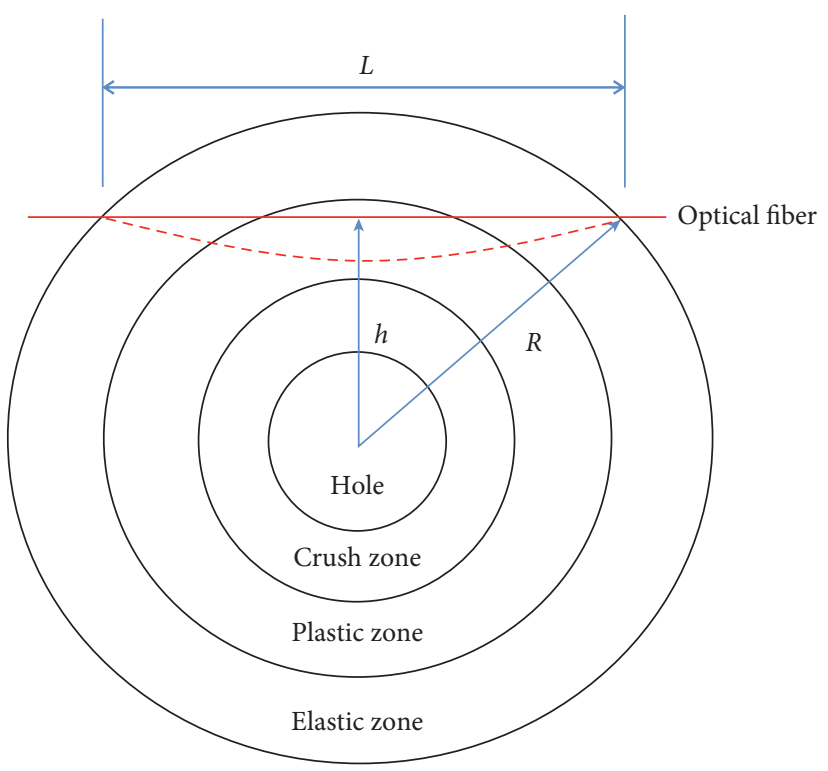

Figure 1: Plane view of the onsite measurement.

working face goaf, and its eastern side is formed by 8941 goaf and Yungang coal mine goaf, as shown in Figure 2. A working face that is adjacent to two goafs like 8939 is often called island working face, which is normally high possibility of coal bump occurrence. Coal bumps occurred several times in tailgates at about $100 \mathrm{~m}$ ahead of 8935 and 8937 working faces [40, 41]. It suggests that the 8939 island face has high coal bump risk.

The average bury depth of 11 \# coal seam is $345 \mathrm{~m}$ with an average coal thickness of $7.5 \mathrm{~m}$ and average inclination angle of $3^{\circ}$. Fully mechanised top coal caving mining method is employed for the 8939 panel; its face length is $95 \mathrm{~m}$, panel length is $1400 \mathrm{~m}$, and pillar width is designed as $20 \mathrm{~m}$. The UCS of the coal is measured as $15.9 \mathrm{MPa}$, and the hardness is of 3.2-4.4 that indicates hard coal seam. The roof and floor of the coal seam are sandstone with UCS $65.4 \mathrm{MPa}$ and 42.7 $\mathrm{MPa}$, respectively.

Pressure relief via rib hole drilling is one major burst control measure in Xinzhouyou coal mine. The hole is designed as $\phi 108 \mathrm{~mm} \times 8.0 \mathrm{~m}$ located $0.5 \mathrm{~m}$ above the floor. The holes are drilled using crawler drilling machine, but the drilling schedule is not strictly defined due to lack of theoretical guideline. Therefore, it is necessary to study pressure relief procedure of the drilling hole for mining safety and economy of the 8939 panel.

3.2. Instrumentation. A $\phi 65 \mathrm{~mm} \times 44 \mathrm{~m}$ monitoring hole was drilled from a winch chamber in 5939 tailgate to install the optical fiber. The chamber is $2 \mathrm{~m}$ depth located $1254 \mathrm{~m}$ from the open-cut of the 8939 panel. The monitoring hole was drilled horizontally at $1.2 \mathrm{~m}$ height and $1.4 \mathrm{~m}$ from the roadway rib. The angle of the optical fiber hole with the rib is $5^{\circ}$, as shown in Figure 3.

Metal strain sensor cable was used to monitoring the deformation of the coal mass. The sensing cable is $\phi 5.0 \pm 0.2 \mathrm{~mm}$ with a maximum tensile force of $2350 \mathrm{~N}$. 


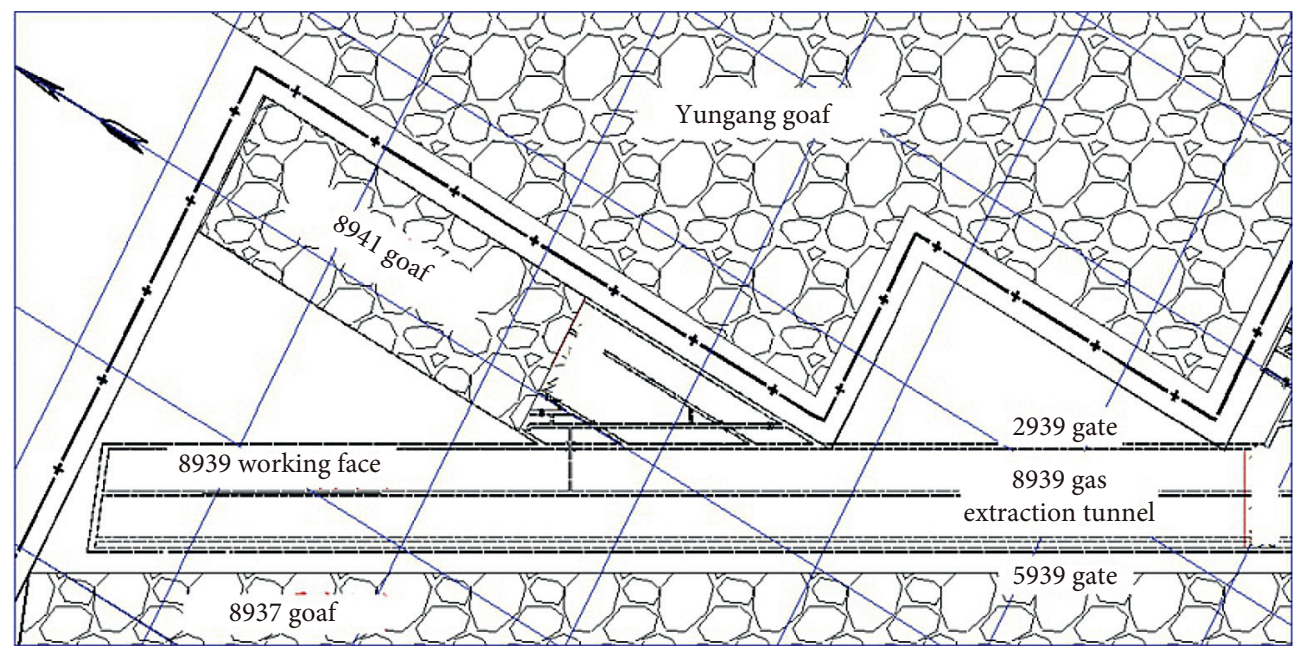

Figure 2: Plan view of no. 8939 panel.

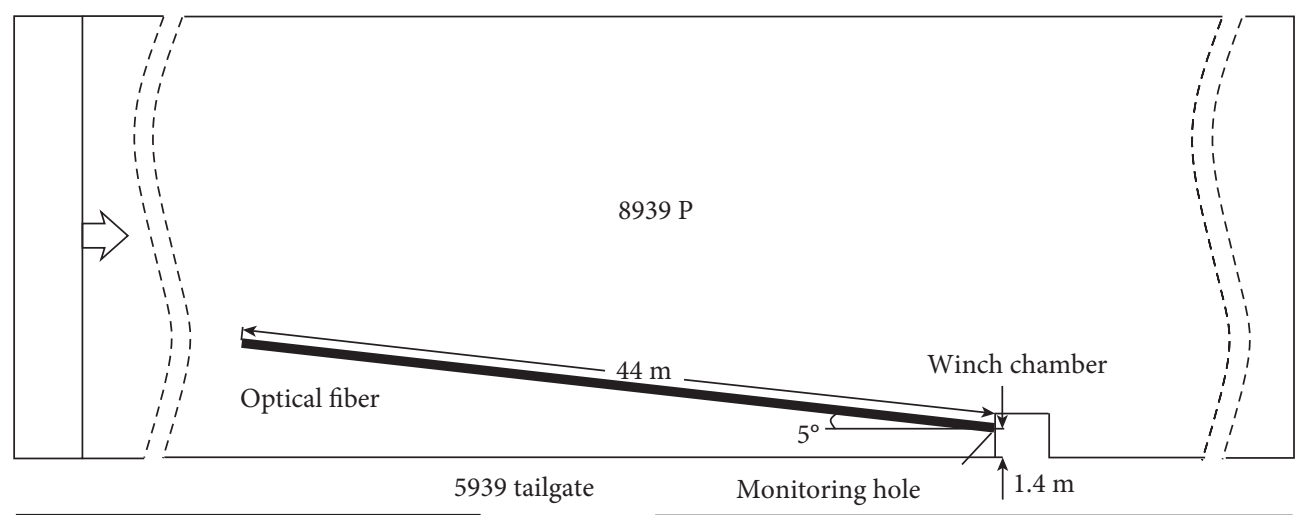

Figure 3: Scheme of monitoring optic fiber.

The fiber was inserted into the monitoring hole using a PVC tube and then cast by cement mortar. According to laboratory test, the elastic modulus of the \#11 coal seam is $3.66 \mathrm{GPa}$ and Poisson's ratio is 0.23 [42], so M7.5 cement mortar that has similar rigidity to the coal was selected to fill the monitoring hole.

3.3. Pressure Relief Holes Layout. A total of 15 pressure relief boreholes were drilled at the length of $6.0 \mathrm{~m}$ and interval of $1.5 \mathrm{~m}$. The hole is $1.0 \mathrm{~m}$ from the floor, i.e., $0.2 \mathrm{~m}$ from the optical fiber. The diameters of the pressure relief hole are selected as $65 \mathrm{~mm}, 90 \mathrm{~mm}$, and $108 \mathrm{~mm}$, and the layout of the hole arrangement is shown in Figure 4.

To confirm the location of the sensor is in accordance with the designing, two rows of detective holes were drilled horizontally at a distance of $40 \mathrm{~m}$ from the optical fiber monitoring orifice, as shown in Figure 4. The row distance is $0.5 \mathrm{~m}$, and the interval of the detective holes is $0.2 \mathrm{~m}$. Apparent strain changes of the sensor cable were measured at this location, indicating that the sensor fiber was installed at the designed position. After confirmation of the monitoring fiber position, the pressure relief holes were drilled perpendicular to the rib surface, as shown in Figure 5.
3.4. Data Collection. AV6419 timely domain optical strain gauge was used to collect the strain of the sensor cable after the hole was filled with cement mortar. The strain was measured 9 times at $0 \mathrm{~h}-480 \mathrm{~h}$ after the completion of the pressure relief hole drilling. The acquisition frequency is set to be $0.1 \mathrm{~m}$, that is, every $0.1 \mathrm{~m}$ fiber length generates one strain data. The field acquisition process is shown in Figure 6.

\section{Results}

4.1. Sensing Cable Strain Analysis. The strain of the sensing cable was measured at $0 \mathrm{~h}, 24 \mathrm{~h}, 72 \mathrm{~h}, 168 \mathrm{~h}, 240 \mathrm{~h}, 288 \mathrm{~h}$, $360 \mathrm{~h}, 432 \mathrm{~h}$, and $480 \mathrm{~h}$ after the completion of the drilling. The full length strain curve of the cable is shown in Figure 7 , whereas the abscissa is the distance of the sensing cable from the origin of the monitoring hole, and the ordinate is the strain of the sensing fiber.

10 \# hole is $19.7 \mathrm{~m}$ from the origin of the optical fiber monitoring hole. Figure 8 shows 10\# pressure relief borehole strain development, which is a typical result for $\phi 108 \mathrm{~mm}$ borehole, the origin of the coordinator is the center of $10 \#$ hole, and positive direction of $x$-axis is towards the working face. 


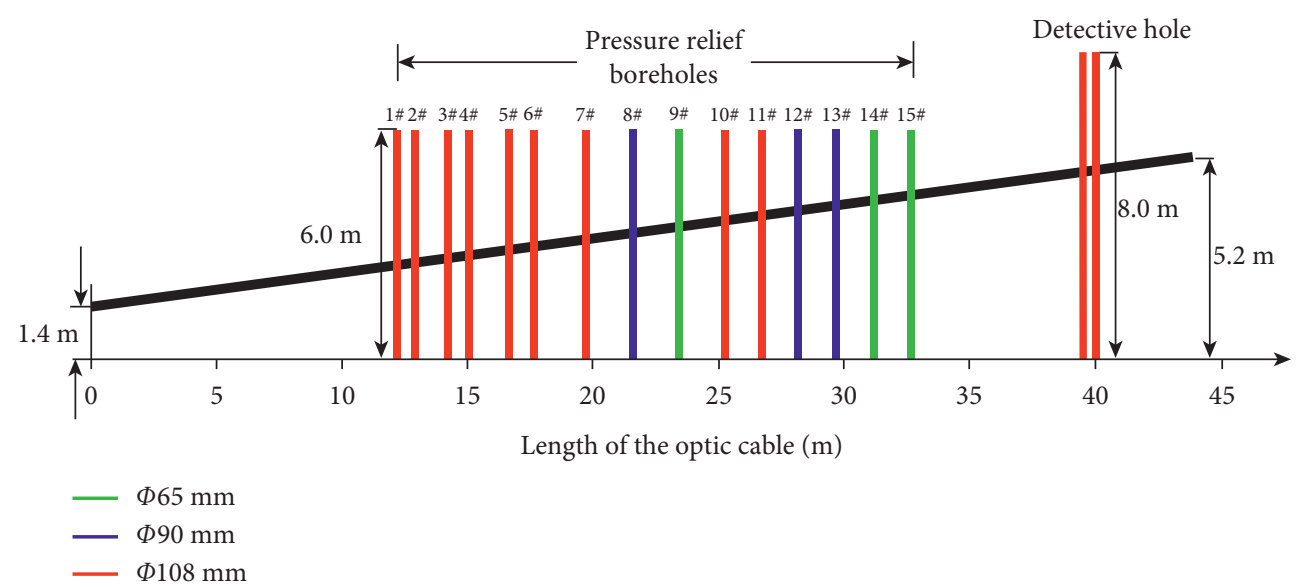

Figure 4: Plan view of pressure relief boreholes layout.

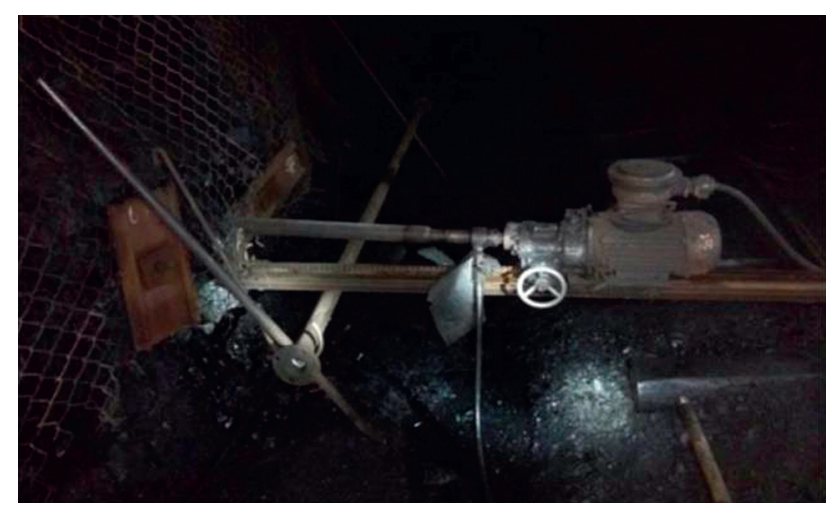

FIgURe 5: Pressure relief borehole drilling in field.

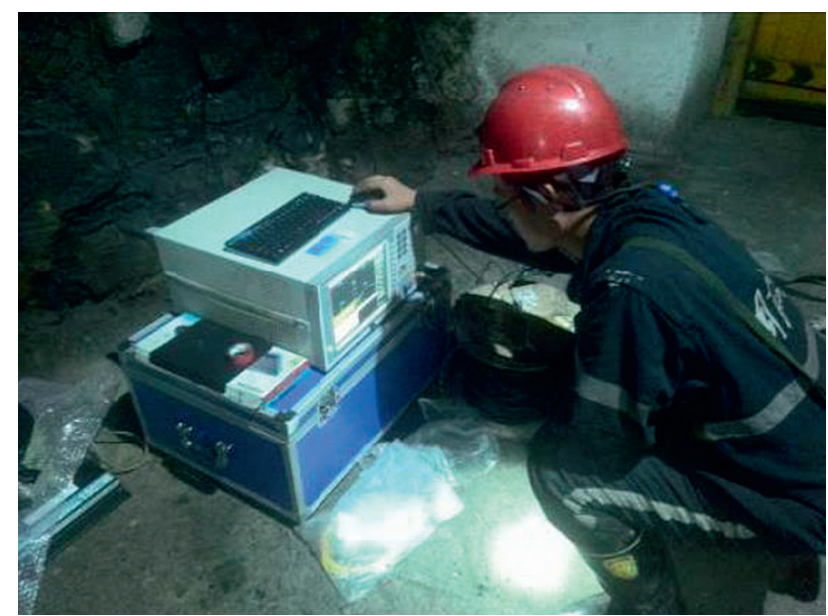

Figure 6: Data acquisition of optical timely domain strain.

Figure 8 shows that the strain is around $10 \mu \varepsilon$ immediately after the hole was drilled. After $24 \mathrm{~h}, 72 \mathrm{~h}$, and $168 \mathrm{~h}$ of drilling, the strain of surrounding coal is small $(<20 \mu \varepsilon)$ with slow increasing of pressure relief range from $0.15 \mathrm{~m}$ to $0.22 \mathrm{~m}$. At the time of $240 \mathrm{~h}$ after drilling, the measured strain was $41 \mu \varepsilon$ and the radius of pressure relief range was $0.40 \mathrm{~m}$, which indicates certain pressure relieving effect. From $288 \mathrm{~h}$ to $360 \mathrm{~h}$ of the hole drilling, the strain changed from $120 \mu \varepsilon$ to $140 \mu \varepsilon$ with the pressure relief radius increasing from $0.55 \mathrm{~m}$ to $0.71 \mathrm{~m}$. This is the stable development of the pressure relief domain. $432 \mathrm{~h}$ after the hole was drilled, the deformation of surrounding coal is measured as $166 \mu \varepsilon$, but the range of pressure relief did not change. At $480 \mathrm{~h}$ of the hole drilling, both the strain and radius did not change, which indicates re-equilibrium of the coal mass.

4.2. Observation of Hole Crush Procedure. In the process of optical fiber measurement, the crush procedure of the borehole was also observed using the hole peeping instrument. After $48 \mathrm{~h}$ of drilling of 10 \# borehole, the wall of the hole is relatively smooth, and no collapse was observed, as shown in Figure 9(a). $168 \mathrm{~h}$ after the hole drilling, partial borehole wall was crushed (Figure 9(b)). After drilling of $240 \mathrm{~h}$, broken coal fell to the bottom of the hole, as shown in Figure 9(c). After drilling for $432 \mathrm{~h}$, the hole is completely collapsed, and broken coal nearly filled all free space of the hole, as shown in Figure 9(d).

According to the results of strain development and observation of the crushing procedure, the pressure relief process via hole drilling can be divided into four stages: crack development stage, limited equilibrium stage, collapse stage, and compaction stage. The characteristics of the borehole for each stage and corresponding duration are shown in Table 1.

4.3. Drilling Optimisation. In reality, due to lack of guideline of drilling schedule, the pressure relief boreholes of the 8939 panel were drilled about 50 70 $\mathrm{m}$ ahead of the working face. According to the results of this study, to achieve the optimal pressure relief effect, the holes should be drilled at least $432 \mathrm{~h}$ ahead of mining-induced pressure. The advancing speed of the 8939 face is about $5-6 \mathrm{~m} / \mathrm{d}$, so the calculated minimum distance of the pressure relief borehole is 94-101 m advance the working face. Later, the pressure relief drilling was arranged as $110 \mathrm{~m}$ ahead of the working face.

SOS microseismic monitoring system is used in the 8939 panel. Figures 10 and 11 show the microseismic events of 48 days before and after changing of drilling schedule. In Figures 10 and 11, 2939 is tailgate, 5939 is maingate, and 8937 and 8941 are goaf. 


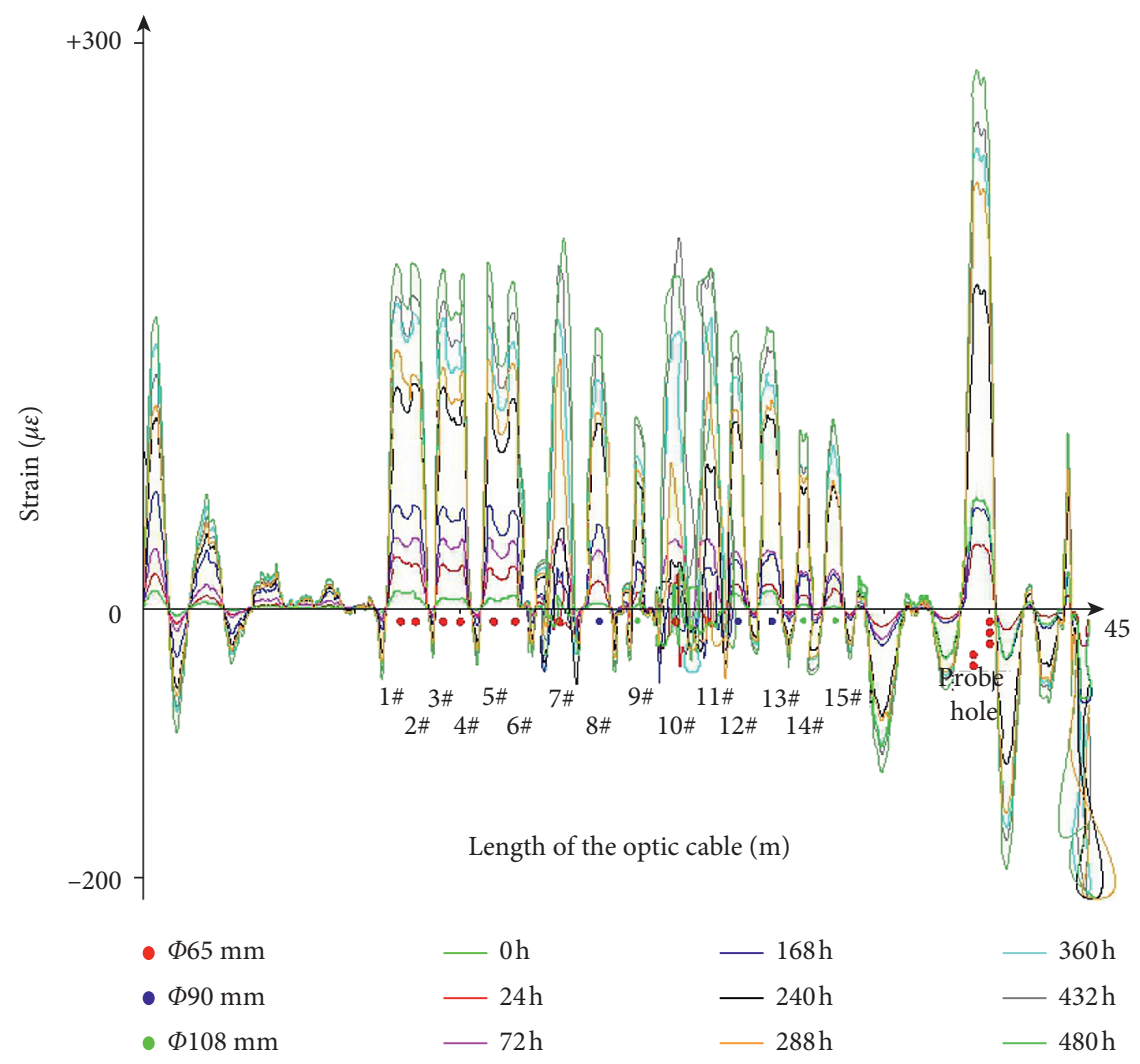

Figure 7: Strain of the whole length of the optic cable.

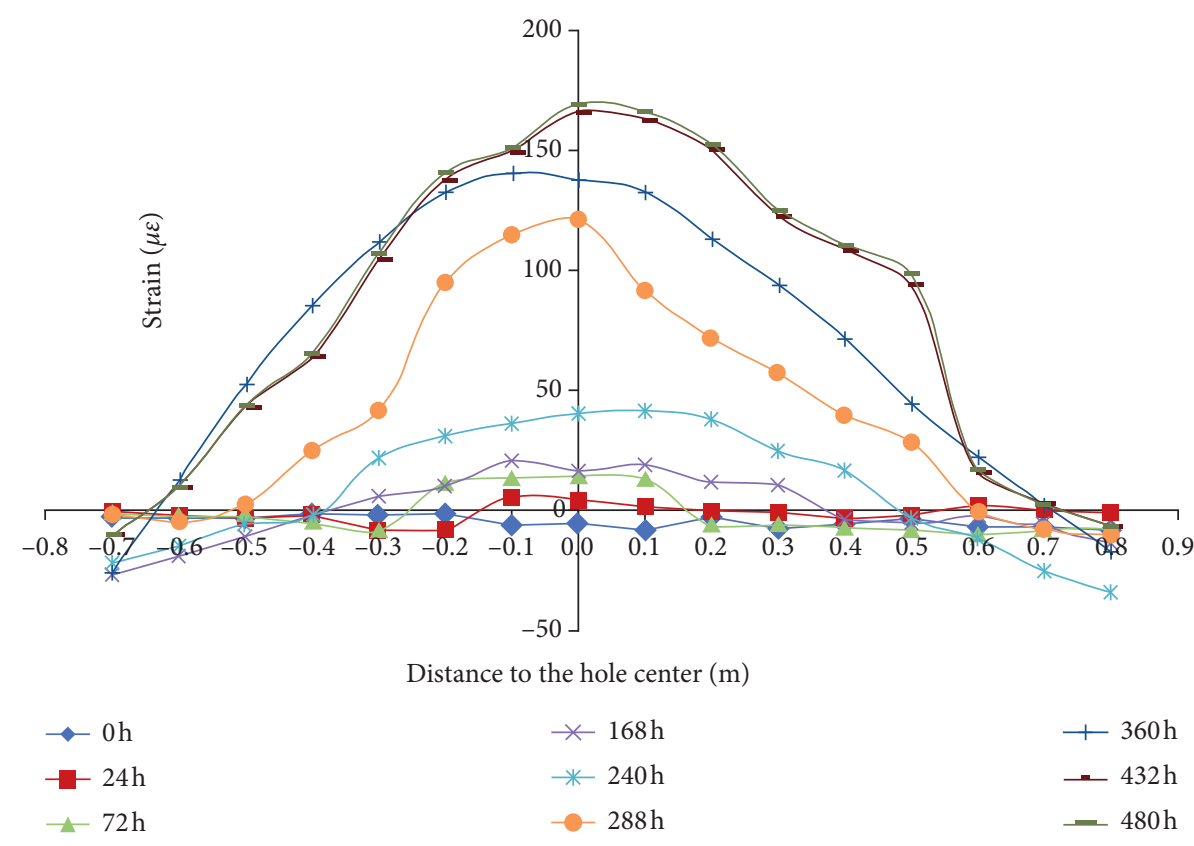

FIGURE 8: Strain curve of 10\# borehole.

Figure 10 shows that there are 58 microseismic events more than $103 \mathrm{~J}$ occurred around the 8939 working face. Among them, 39 events are 103-104 J, 13 events are 104-
$105 \mathrm{~J}$, and 6 events are greater than $105 \mathrm{~J}$. Two $105 \mathrm{~J}$ events caused floor heave at a height of $0.5-0.8 \mathrm{~m}$ along $200 \mathrm{~m}$ roadway, and 5 support posts were broken. 


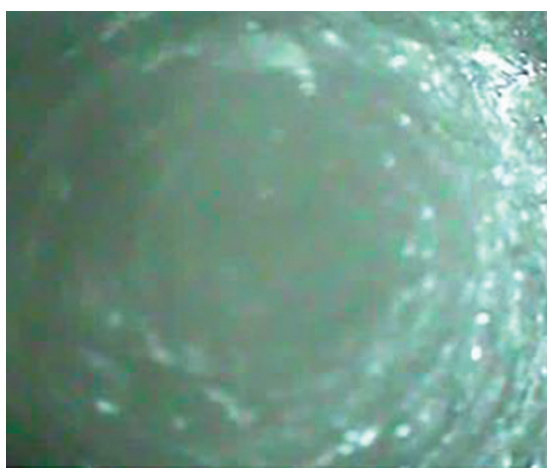

(a)

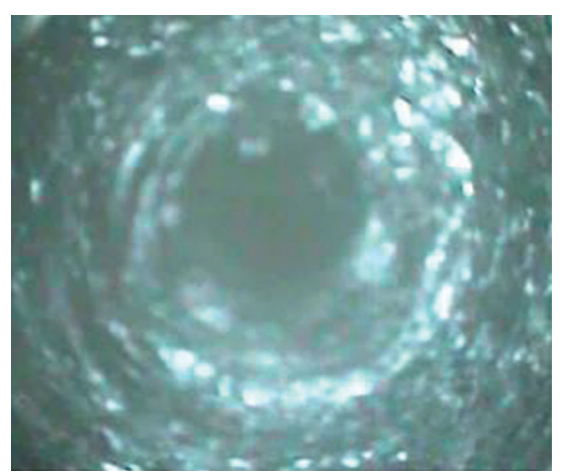

(b)

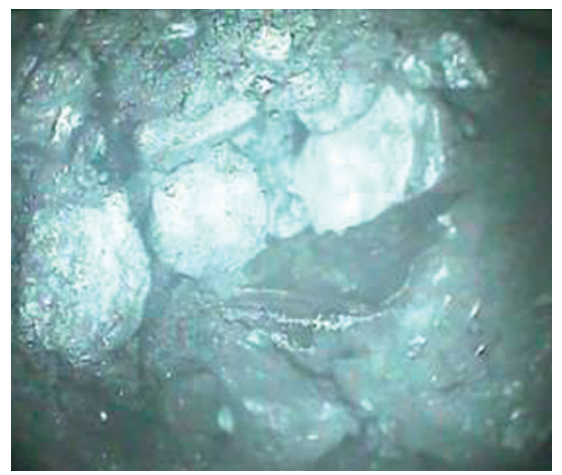

(d)

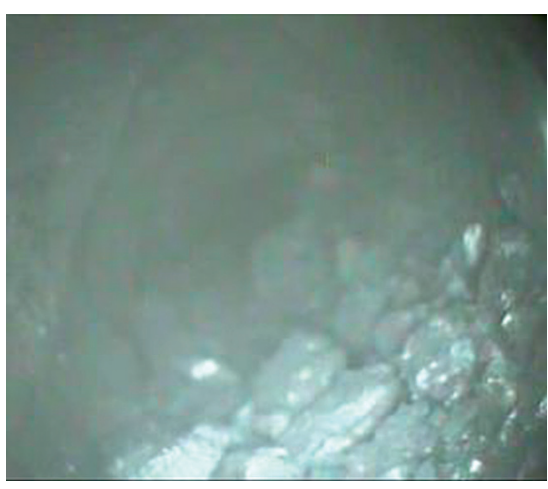

(c)

Figure 9: Observation of 10\# borehole. (a) 48 h. (b) 168 h. (c) 240 h. (d) 432 h.

TABLE 1: Characteristics of borehole development.

\begin{tabular}{lccc}
\hline Stage & Deformational behaviour & Observation & Duration \\
\hline Crack development & Small strain, increasing of radius & Smooth hole wall & $0 \sim 72 \mathrm{~h}$ \\
Limited equilibrium & Slow increase of strain and radius & Coarse hole wall but no collapse & $72 \sim 190 \mathrm{~h}$ \\
Collapse & Linear increase of strain and radius & Collapse of the hole & $190 \sim 402 \mathrm{~h}$ \\
Compaction & Slow increase of strain but radius does not increase & Hole fulfilled by broken coal & $>402 \mathrm{~h}$ \\
\hline
\end{tabular}

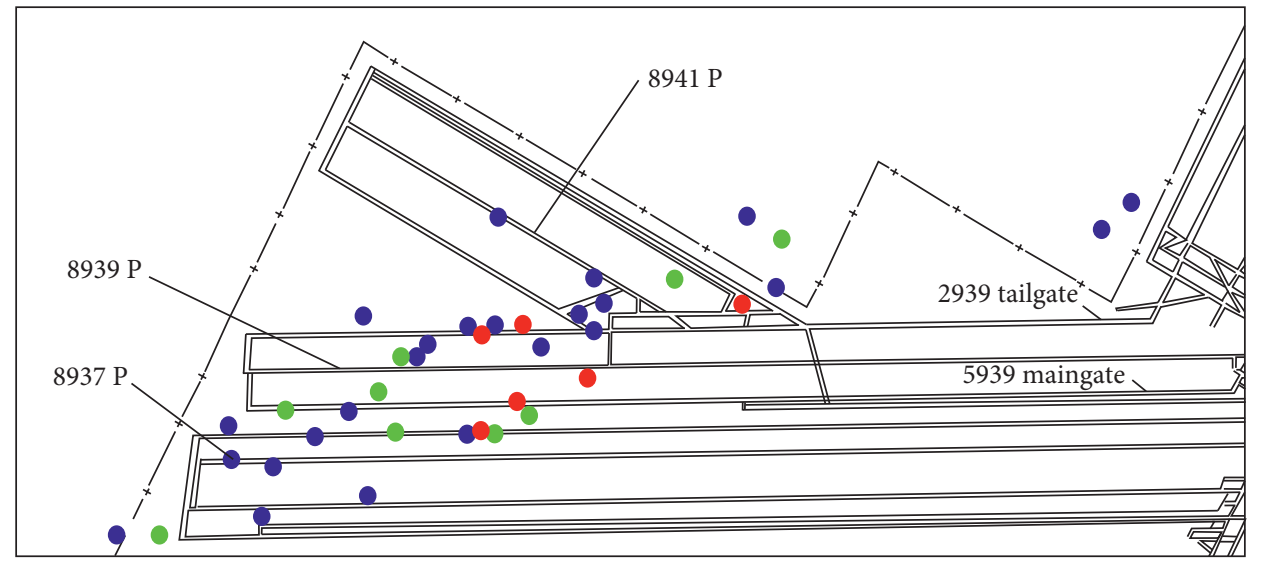
- $>10^{3} \mathrm{~J}$
$>10^{4} \mathrm{~J}$
$>10^{5} \mathrm{~J}$

Figure 10: Microseismic event distribution before adjustment of borehole constructed time. 


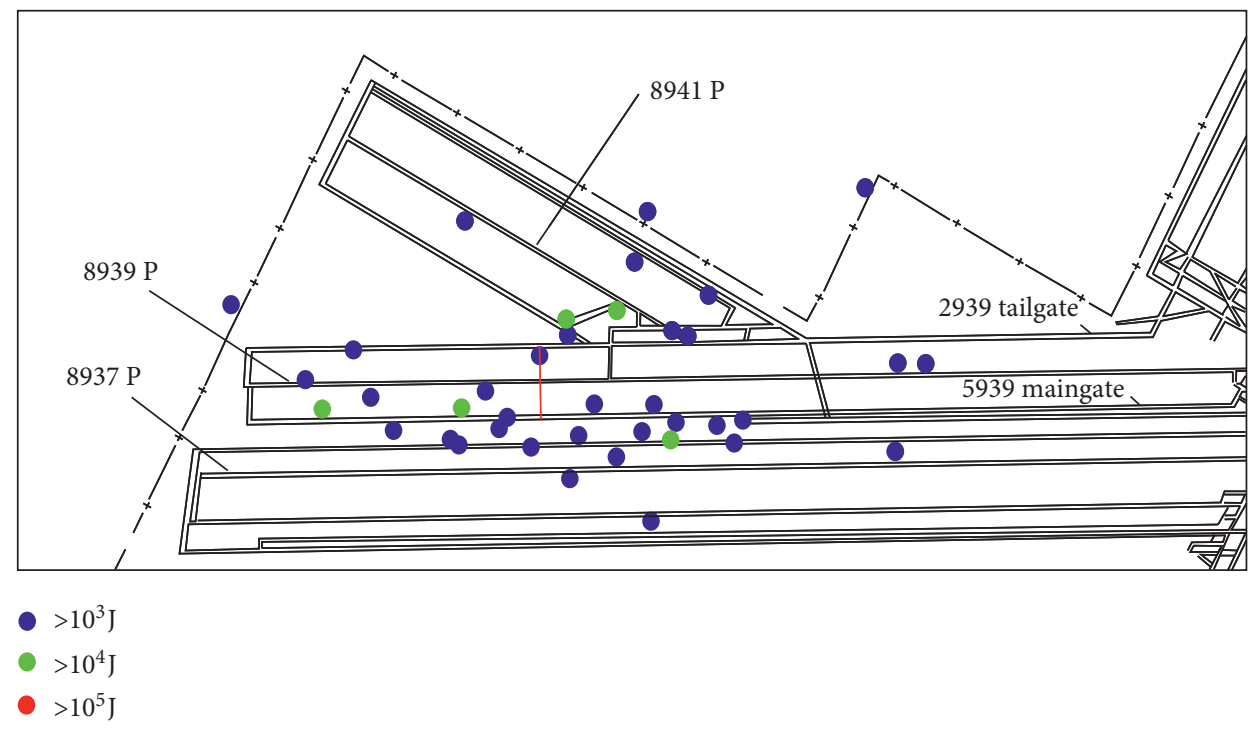

Figure 11: Microseismic event distribution after adjustment of borehole constructed time.

After rearrangement of the drilling schedule of the pressure relief borehole, the microseismic events more than $103 \mathrm{~J}$ occurred 62 times around the 8939 working face (Figure 11). Among them, 49 events are 103-104 J, 13 events are 104-105 J, and no events are greater than $105 \mathrm{~J}$. Compared with previous drilling layout, the average energy of microseismic events reduced by about $38 \%$. Consequently, floor heave did not occur since then on.

\section{Conclusions}

This paper provides a case study of the deformational behaviour of the pressure relief borehole using distributed optical fiber sensing technology. The strain of the surrounding coal was measured, and the radius of the pressure relief range was calculated. Based on the strain magnitude and pressure relief range, the effect of borehole drilling is evaluated. Combining with borehole internal observation, the crush procedure of pressure relief borehole is identified as four stages: crack development, limited equilibrium, collapse, and compaction.

The 8939 working face of Xinzhouyao coal mine is a high coalbump proneness panel. Based on the analysis of pressure relief procedure of the hole, the fracturing development stage, limited equilibrium stage, collapse stage, and broken coal compaction stage were estimated as $0 \sim 72 \mathrm{~h}, 72 \sim 190 \mathrm{~h}$, $190 \sim 402 \mathrm{~h}$, and greater than $402 \mathrm{~h}$, respectively. Accordingly, to achieve better pressure relief effect, the borehole should be drilled $110 \mathrm{~m}$ ahead of the working face. Microseismic event monitoring shows that, after hole drilling optimasation, the high-energy microseismic events and average energy of microseismic events are reduced significantly.

\section{Data Availability}

All data of this article have been included in this manuscript.

\section{Conflicts of Interest}

The authors declare that there are no conflicts of interest regarding the publication of this paper.

\section{References}

[1] H. Lan, Q. X. Qi, and J. F. Pan, "Analysis on features as well as prevention and control technology of mine strata pressure bumping in China," Coal Science and Technology, vol. 39, no. 1, pp. 11-15, 2011.

[2] Y. D. Jiang and Y. X. Zhao, "State of the art: investigation on mechanism, forecast and control of coal bumps in China," Chinese Journal of Rock Mechanics and Engineering, vol. 34, no. 11, pp. 2188-2204, 2015.

[3] J. Lin, T. Ren, and Y. P. Cheng, "Cyclic N2 injection for enhanced coal seam gas recovery: a laboratory study," Energy, vol. 188, Article ID 116115, 2019.

[4] L. Zhang, J. H. Li, and J. H. Xue, "Experimental studies on the changing characteristics of the gas flow capacity on bituminous coal in CO2-ECBM and N2-ECBM," Fuel, vol. 291, Article ID 120115, 2021.

[5] H. Lan, D. K. Chen, and D. B. Mao, "Current status of deep mining and disaster prevention in China," Coal Science and Technology, vol. 44, no. 1, pp. 39-46, 2016.

[6] H. W. Zhang, F. Zhu, and J. Han, "Geological dynamic conditions and forecast technology for rock bursts," Journal of China Coal Society, vol. 41, no. 3, pp. 45-51, 2016.

[7] B. Chen, "Stress-induced trend: the clustering feature of coal mine disasters and earthquakes in China," International Journal of Coal Science \& Technology, vol. 7, no. 4, pp. 676692, 2020.

[8] A. Li, F. Dai, and H. B. Du, "Dynamic stability evaluation of underground cavern sidewalls against flexural toppling considering excavation-induced damage," Tunnelling and Underground Space Technology, vol. 112, Article ID 103903, 2021.

[9] X. W. Feng, N. Zhang, and F. Xue, "Practices, experience, and lessons learned based on field observations of support failures in some Chinese coal mines," International Journal of Rock 
Mechanics and Mining Sciences, vol. 123, Article ID 104097, 2019.

[10] D. J. Xue, J. Zhou, and Y. T. Liu, "On the excavation-induced stress drop in damaged coal considering a coupled yield and failure criterion," International Journal of Coal Science \& Technology, vol. 7, no. 5, pp. 58-67, 2020.

[11] Y. Wang, W. K. Feng, R. L. Hu, and C. H. Li, "Fracture evolution and energy characteristics during marble failure under triaxial fatigue cyclic and confining pressure unloading (FC-CPU) conditions," Rock Mechanics and Rock Engineering, vol. 54, no. 2, pp. 799-818, 2021.

[12] Y. D. Jiang, Y. S. Pan, and F. X. Jiang, "State of the art review on mechanism and prevention of coal bumps in China," Journal of China Coal Society, vol. 39, no. 2, pp. 205-213, 2014.

[13] J. Lin, T. Ren, G. Wang, P. Booth, and J. Nemcik, "Experimental investigation of $\mathrm{N} 2$ injection to enhance gas drainage in CO2-rich low permeable seam," Fuel, vol. 215, pp. 665-674, 2018.

[14] L. Zhang, S. Chen, and C. Zhang, "The characterization of bituminous coal microstructure and permeability by liquid nitrogen fracturing based on $\mu \mathrm{CT}$ technology," Fuel, vol. 262, Article ID 116635, 2020.

[15] D. J. Xue, H. W. Zhou, Y. T. Liu, L. S. Deng, and L. Zhang, "Study of drainage and percolation of nitrogen-water flooding in tight coal by NMR imaging," Rock Mechanics and Rock Engineering, vol. 51, no. 11, pp. 3421-3437, 2018.

[16] J. Wang, J. Yang, F. Wu, T. Hu, and S. A. Faisal, “Analysis of fracture mechanism for surrounding rock hole based on water-filled blasting," International Journal of Coal Science \& Technology, vol. 7, no. 4, pp. 704-713, 2020.

[17] M. G. Qian, P. W. Shi, and J. L. Xu, Ground Stress and Strate Contral, CUMT, Xuzhou, China, 2010.

[18] S. T. Zhu, F. X. Jiang, and X. F. Shi, "Energy dissipation index method for determining rockburst prevention drilling parameters," Rock and Soil Mechanics, vol. 36, no. 8, pp. 2270-2276, 2015.

[19] Z. Q. Ma, Y. D. Jiang, and Y. W. Li, "Collaborative control of pressure released boreholes with U-steel of roadways in ul-trasoft coal seam," Journal of China Coal Society, vol. 40, no. 10, pp. 2279-2286, 2015.

[20] M. M. Geng, Z. G. Ma, and P. Gong, "Analysis of the effect on pressure relief by the pressure relieving hole layouts in high stress coal roadway," Journal of Safety Science and Technology, vol. 8, no. 11, pp. 5-10, 2012.

[21] E. B. Yi, Z. L. Mou, and L. M. Dou, "Study on comparison and analysis on pressure releasing effect of boreholes in soft and hard seam," Coal Science and Technology, vol. 39, no. 6, pp. 1-5, 2011.

[22] Y. W. Lan, H. M. Gao, and X. H. Chen, "Numerical simulation study on influence factors of borehole pressure relief effect," Mining Safety \& Environment Protection, vol. 40, no. 3, pp. 6-9, 2013.

[23] H. G. Liu, Y. N. He, and J. H. Xu, "Numerical simulation and industrial test of boreholes destressing technology in deep coal tunnel," Journal of China Coal Society, vol. 32, no. 1, pp. 33-37, 2007.

[24] X. Wu, D. S. Zhang, and X. F. Wang, "Analysis of pressure relief boreholes on 3DEC simulation in deep and high stress roadway," Safety In Coal Mines, vol. 39, no. 10, pp. 51-53, 2008.
[25] D. Xue, H. Zhou, Y. Zhao, L. Zhang, L. Deng, and X. Wang, "Real-time SEM observation of mesoscale failures under thermal-mechanical coupling sequences in granite," International Journal of Rock Mechanics and Mining Sciences, vol. 112, pp. 35-46, 2018.

[26] X. Cheng, "Damage and failure characteristics of rock similar materials with pre-existing cracks," International Journal of Coal Science \& Technology, vol. 6, no. 4, pp. 505-517, 2019.

[27] X. Bao and L. Chen, "Recent progress in brillouin scattering based fiber sensors," Sensors, vol. 11, no. 4, pp. 4152-4187, 2011.

[28] Q. X. Meng, W. Y. Wu, and H. L. Wang, "DigiSim-an open source software package for heterogeneous material modeling based on digital image processing," Advances in Engineering Software, vol. 148, Article ID 102836, 2020.

[29] D. J. Xue, Y. T. Liu, H. W. Zhou, J. Q. Wang, J. F. Liu, and J. Zhou, "Fractal characterization on anisotropy and fractal reconstruction of rough surface of granite under orthogonal shear," Rock Mechanics and Rock Engineering, vol. 53, no. 3, pp. 1225-1242, 2020.

[30] H. Ren, Y. Zhao, W. Xiao, and Z. Hu, "A review of UAV monitoring in mining areas: current status and future perspectives," International Journal of Coal Science \& Technology, vol. 6 , no. 3, pp. 320-333, 2019.

[31] D. J. Xue, L. L. Lu, and J. Zhou, "Cluster modeling of the short-range correlation of acoustically emitted scattering signals," International Journal of Coal Science \& Technology, vol. 53, pp. 1-15, 2020.

[32] D. Zhang, P. S. Zhang, and B. Shi, "Monitoring and analysis of overburden deformation and failure using distributed," Fiber Optic Sensing, vol. 37, no. 5, pp. 952-957, 2015.

[33] B. Shi, H. Z. Xu, and D. Zhang, "Feasibility study on application of BOTDR to health monitoring for large infrastructure engineering," Chinese Journal of Rock Mechanics and Engineering, vol. 23, no. 3, pp. 493-499, 2004.

[34] H. L. Kou, M. Y. Zhang, and J. W. Liu, "Bearing capacity efficiency mechanism analysis of jacked pile based on optical fiber sensing technology," Rock and Soil Mechanics, vol. 34, no. 4, pp. 1082-1088, 2013.

[35] G. Q. Wei, B. Shi, and X. K. Yu, "BOTDR based distributed strain test on bored pile buried in complicated geological ground," Journal of Engineering Geology, vol. 16, no. 6, pp. 826-832, 2008.

[36] G. Q. Wei, B. Shi, and J. X. Jia, "Application of distributed optical fiber sensing to testing inner force of prefabricated piles," Chinese Journal of Geotechnical Engineering, vol. 31, no. 6, pp. 911-916, 2009.

[37] D. XueJ. Wang et al., "Quantitative determination of mininginduced discontinuous stress drop in coal," International Journal of Rock Mechanics and Mining Sciences, vol. 111, pp. 1-11, 2018.

[38] Z. Xu, Elastic Mechnics, Tertiary Education Publisher, " Beijing, China, 2013.

[39] J. Han, H. Liang, C. Cao, Z. Bi, and Z. Zhu, "A mechanical model for sheared joints based on Mohr-Coulomb material properties," Géotechnique Letters, vol. 8, no. 2, pp. 92-96, 2018.

[40] B. Yu, Y. Chen, and J. Han, "Study of the relationship between the Kouquan fault and strongground pressure in TongxinCoal Mine," Journal of China Coal Society, vol. 38, no. 1, pp. 73-77, 2013. 
[41] X. H. Wang, "Research on the Mechanism of Rock Burst Occurring in "Three Hard" Coal Seam of Datong Coal Mining Area, Taiyuan University of Technology, Taiyuan, China, 2010.

[42] H. W. Zhang, Y. P. Li, and Y. Chen, "Study on safety pushing forward speed of island coal mining face under hard roof and hard seam and hard floor conditions," Coal Science and Technology, vol. 45, no. 2, pp. 6-11, 2017. 